\title{
Determining Copyright Status for Preservation and Access: Defining Reasonable Effort
}

\section{Samuel Demas and Jennie L. Brogdon}

\begin{abstract}
Alternative procedures were investigated for determining the copyright status of brittle monographs to be scanned as part of the national preservation plan for agricultural sciences literature. Copyright searches were conducted both in Washington in the files of the U.S. Copyright Office and at Cornell University in the printed Catalog of Copyright Entries (CCE). Results were compared to determine the most efficient procedure. Search procedures (averaging 7 minutes per title) in the CCE were 97\% in agreement overall with the results obtained from conside rably more time consuming (13 minutes per title) searching at the Copyright Office. CCE searches were $100 \%$ in agreement concerning instances of renewal of copyright. This finding calls into question the assumption that it is necessary to conduct such searches at considerable cost in the complex files of the Copyright Office. The resulting CCE search procedure is suggested as a standard of reasonable effort for copyright searching, which demonstrates a legally responsible reasonable effort to respect the rights of copyright holders while advancing preservation aims and converting carefully selected print materials to build the digital library.
\end{abstract}

$\mathbf{L}$

ibrarians hope to reformat large numbers of books in the coming decades to preserve and enhance access to a selected part of the published record. Some portion of the existing printed record in each discipline will be selected for scanning to become part of the emerging digital library, and some portion will be selected for conversion to less flexible, but more stable formats for preservation purposes.
Similarly, a portion of the record-both print and digital-will be privileged by selection for digital archiving. By and large, current selection methodologies for this mammoth task are primitive, disjointed, serendipitous, and opportunistic. Regardless of the selection methods used and the technologies employed for converting books and making copies of them, this multi-generational challenge of

Samuel Demas (sgd1@cornell.edu) is Head of Collection Development and Preservation at Albert R. Mann Library, Cornell University. JENNIE L. BroGDON is retired from the National Agricultural Library. The authors are deeply indebted to Jan Kennedy Olsen and Wallace C. Olsen. The authors are also grateful for the assistance of Stephanie Lamson, preservation technician. The authors appreciate the comments and suggestions of reviewers: Stephen Chapman, Rich Entlich, Carl Fleischhauer, Anne Kenney, Ellen R. McCrady, and Robert L. Oakley. Manuscript received July 16, 1997; accepted for publication August 28, 1997. 
building the digital library will involve an immense task in copyright clearance for U.S. works published in the past 75 years. To conduct large-scale conversion projects, librarians will need cost-effective, legally responsible procedures for determining the copyright status of works, finding the address of copyright owners of materials still protected, and seeking permission to make and distribute multiple copies.

A curious lack of systematic investigation of these tasks by the library community has effectively stymied large-scale library-based efforts to preserve brittle U.S. books and journals published in the past 75 years and that may therefore still be protected by copyright. While private sector enterprises such as UMI have established successful copyright permissions mechanisms, most library preservation projects are carefully designed to avoid the issue by largely ignoring U.S. imprints published after 1920. The library, publishing, and author communities must eventually come to agreement on a set of procedures that will allow libraries to proceed responsibly with the preservation of deteriorating twentieth century U.S. publications. To that end, we propose a procedure for the first steps in any copyright investigation: determining the copyright status of a work and, if the work is still under copyright protection, finding the address of the copyright owner listed in the copyright registration.

In the course of preserving the core historical literature of the agricultural sciences for the time period from 1860 to 1950, librarians at the Albert R. Mann Library, Cornell University, conducted a pilot project to develop scalable, costeffective, and legally defensible procedures for determining the copyright status of U.S. monographs published between 1920 and 1950 . The 1950 cutoff date cor responds to the parameters of the body of literature selected for conversion. Procedures for searching monographs published between 1950 and 1978 are not specifi cally treated in this paper, though they are very similar to those for works published between 1920 and 1950. The procedures developed in this project are presented here as a standard of reasonable effort for use by the library community in national cooperative preservation efforts.

\section{Identifying and Preserving Core historical Literature}

The copyright investigation that is described here was an outgrowth of a project conducted at the Mann Library to identify and preserve the Core Historical Literature of the Agricultural Sciences. Gwinn (1993) identified the broad heritage groups of agricultural literature, which included various publications that were both in and out of copyright. At the heart of this national heritage literature was the Core Historical Literature of the Agricultural Sciences, which constituted the most significant scholarly books and journals in the field.

The core project at the Mann Library was conducted from 1988 to 1993 to identify specific titles that constituted this core; that project, titled the Core Agricultural Literature Project, was directed by Wallace C. Olsen. The selection of titles in this project involved citation analysis of the literature coupled with an evaluation of the resulting lists by panels of experts in each of seven disciplines. Over 600 scientists and scholars worldwide participated in the evaluation of the lists. The methodology for selecting both the contemporary (post-1950) and historic (18601950) literature was developed by Olsen with funds from the Rockefeller Foundation, the Comell Agricultural Experiment Station, and the National Agricultural Library. The bibliographies that resulted from this project were published by the Cornell University Press in a seven-volume set, The Literature of the Agricultural Sciences, Wallace C. Olsen, Series Editor.

In each volume, the literature of a specific discipline is analyzed and evaluated. Each volume includes a chapter that lists the historical monographs and serials given top priority for preservation by the panels. For a discussion of the selection method that was used, see Olsen (1991); Thompson and Hall (1992); and Murphy and Wright (1993). The seven disciplines 
TABLE 1.

Core Historical Literature of the Agricultural Sciences, 1860-1950

\begin{tabular}{lccr}
\hline Discipline & Monograph Titles & Journal Titles & Total \\
\hline Agricultural Engineering & 676 & 42 & 718 \\
Animal Science & 625 & 72 & 697 \\
Crop Improvement and Protection & 1,074 & 81 & 1,155 \\
Food Science and Human Nutrition & 572 & 38 & 610 \\
Forestry & 349 & 41 & 390 \\
Soils & 414 & 27 & 441 \\
TOTAL & 4,494 & 339 & 4,833 \\
\hline
\end{tabular}

and a count of the core historical monographs and serials are presented in table 1 .

Thus, within the wider framework of the national preservation plan outlined by Gwinn (1993), Mann Library has accepted responsibility for preserving this Core Historical Literature, which includes 4,833 titles in over 18,000 volumes. The premise of the current project is that selection for preservation must systematically address the literature of disciplines, rather than focus on the holdings of specific libraries (Demas 1994).

The entire corpus will be reformatted in three forms: paper facsimiles, archival microfilm, and digital files. Where possible, existing microfilm will be scanned, and titles not yet filmed are being scanned. Raster computer output microfilm will then be produced from the digital files.

A key goal of this project is the not-forprofit digital distribution of the complete heritage literature to land grant and other interested libraries. In this way, the entire Core Historical Literature will be preserved in one project and all libraries can share the results. This coordinated approach will allow other agricultural libraries to target their limited preservation resources to other parts of the literature.

Scanning and distributing copyrighted materials require that permission be obtained; therefore, it is essential first to determine whether or not a work is copyrighted. While the potential market for and expected revenues from all but a very few pre-1950 copyrighted works is small, the law grants copyright holders the exclusive right to make multiple copies of their works. A successful national preservation effort, however, will involve making multiple copies of protected works, and will therefore require negotiations with authors and publishers for certain rights in the use of digital or microfilm copies. We believe these discussions should be informed by empirical data and systematic investigation, and hence, we initiated this pilot project.

\section{How to Determine COPYRIGHT STATUS}

Generally speaking, books published prior to the Copyright Act of 1976 received an initial 28-year copyright and could be renewed for an additional 47 years, for a total of 75 years of copyright protection (Oakley 1990). (This is an oversimplification of the law, but an accurate statement nonetheless. No attempt is made here to provide detailed explanations of the copyright law. Readers interested in the nuances and complexities of copyright law are encouraged to read Oakley (1990), which provides an excellent overview of the copyright law in relation to preservation.) A copyright search is necessary to determine whether a work was ever registered for copyright, and, if so, whether the copyright was ever renewed. According to a 1961 Copyright 
Office report, $90.5 \%$ of copyrights on all forms of materials copyrighted during the study period were not renewed (Guinan 1961). In this same study, the renewal rate on the subset of copyrighted books and pamphlets was found to be only $4.1 \%$. So while permissions must be sought on only a fraction of the titles, how does one identify the specific titles still copyrighted, and how does one find the names and addresses of the copyright owners?

Oakley's (1990) detailed analysis of the U.S. copyright scheme and its relation to preservation, and his thoughtful discussion of possible solutions were extremely useful in understanding the broader context of the problem we faced. However, Oakley offered little guidance on the specific issue of how best to determine copyright status on a large body of works.

The U.S. Copyright Office (1994, p.3) recommends three methods of determining copyright status:

1. Examine a copy of the work for such elements as a copyright notice, place and date of publication.

2. Make a search of the Copyright Office catalogs and other records; or

3. Have the Copyright Office make a search for you.

Copyright investigations often involve more than one of these methods.

It is further explained that copyright searches can be conducted in the records housed in the Copyright Office and in the printed Catalog of Copyright Entries (CCE). The CCE, sold by the Government Printing Office and held in many U.S. libraries (including Comell University), is an authoritative record of copyrights. This tool seemed ideal for the purposes of our preservation project. However, the introductory instructions in the article are immediately followed with the caution that "Even if you follow all three approaches, the results may not be conclusive" (Library of Congress 1994, p.3).

It was unclear to us from the instructions under what circumstances searching the $C C E$ was an acceptable alternative to searching the catalogs and other records located in Washington, and we were puzzled by the caveat that even after trying all three approaches the results may not be conclusive. Phone calls to the Copyright Office revealed a strange puzzle: no one could (or would) say that it was acceptable to search only the CCE for purposes of determining copyright status on monographs published between 1920 and 1950 . There appeared to be no evidence forthcoming from the Copyright Office on which to base a clear and authoritative ruling on the reliability of the CCE for our purposes (i.e., whether it was comprehensive enough to serve as a sole source for copyright status searches). We soon discovered that Oakley (1990, p.14) reflects the common wisdom on procedures for determining copyright status:

[W]orks published prior to 1915 can be presumed to be in the public domain. Similarly, works published after 1978 can be presumed to be protected. For works published between those dates, some research at the Copyright Office is likely to be necessary to determine whether the work was registered, by whom, and whether or not it was renewed. (emphasis added)

Some context for this quotation is important: 1915 is 75 years before 1990 , the date of Oakley's report. What Oakley meant, in more general terms, is that works published more than 75 years agothe duration of copyright protection for published works-are in the public domain. For example, on January 1, 1995, we can safely assume that works published before January 1, 1920 are in the public domain.

A literature search turned up no publications on procedures for determining copyright status on a large scale. Phone inquiries to colleagues in the preservation community yielded little in the way of practical guidance for determining copyright status and indicated considerable uncertainty about the topic. Given the general uncertainty surrounding what constitutes a sufficient copyright search and a reasonable effort, Oakley suggested in a February 1, 1994 phone interview with us that at the beginning of a project such as ours contingency funds be set aside for the purpose of settling claims if we wrongly assumed that copyright had lapsed on a title scanned for distribution. 
We weren't sure how to proceed. Sending a staff member to Washington to search thousands of titles in the complex files of the Copyright Office seemed an unreasonable burden. We investigated paying the Copyright Office to have the work done by their staff (and waiting months in their queue) or contracting with a commercial search firm. These approaches were prohibitively expensive and time consuming. We concluded that while it seemed likely to us that one could reliably determine whether a work is protected by copyright without research at the Copyright Office in Washington, D.C., it seemed imprudent to rely on the CCE alone without strong evidence to support this decision. In view of the size and national scope of our project, we felt obliged to take a legally scrupulous course, clearly demonstrating reasonable effort to comply with the law. In the absence of a standard of reasonable effort specifying the nature and extent of a reasonable and sufficient copyright search for our purposes, we decided to develop one ourselves.

To address the issue empirically, we conducted our own careful study of the problem by devising a pilot project, conducted in 1994, with the following objectives:

1. Obtain estimate of the percentage of titles which remain under copyright protection;

2. Find the most efficient and legally sufficient procedures for:

a. determining copyright status of U.S. monographs published between 1920 and 1950 , and

b. finding the names and addresses of copyright holders; and

3. Assess the level of effort and cost required for these procedures.

Based on the data and experience gained in the pilot investigation, we developed a legally defensible, cost-effective procedure to use in this preservation project.

\section{METHOD}

SAMPLE

The materials selected for the project included a total of 4,494 monographic titles.
Of these, $42 \%$ were published before 1920, are now in the public domain, and were excluded from the study. The remaining 2,608 monographs published between 1920 and 1950 were the focus of our investigation. A random sample of 370 titles from agricultural economics and rural sociology was selected for intensive, comparative copyright searching to determine the optimal search procedures.

\section{SEARCHING BACKGROUND}

The method employed in this pilot investigation was to search each of the 370 titles twice: first at Cornell in the published $C C E$, and then in the various catalogs and registers located in the Copyright Office itself. A careful comparison of the results of both searches would reveal the adequacy of simply searching the $C C E$.

The technique for searching copyright status at the Copyright Office was developed during two preliminary visits there by Brogdon. Professional staff of the Reference and Bibliography Section of the Copyright Office were most helpful in explaining the search procedures, answering questions, and explaining additional procedures as the searching progressed.

Searching in the $C C E$ at Cornell was conducted by a combination of student assistants and preservation technicians. The searched lists were then sent to Brogdon for extensive searching at the Copyright Office. The search methods used in each approach are outlined below.

\section{Preliminaty Searching in the Published CCE AT CORNELL}

The CCE is available in printed form to 1979. Since then it has been issued in microfiche and online. The CCE is divided into parts according to the classes of works registered; for the publications in this study, the class was "Books." Each volume of the $C C E$ contains entries for registrations made during a particular year, with the renewals in a separate section.

Works in the study could have been copyrighted at any time during the first 28 
years. However, for this preliminary searching, the author and title were searched in the CCE only for the year of publication, the rationale being that the subsequent 27 years could be searched faster in the copyright card catalogs. Later comparison of the local search results with those at the Copyright Office revealed how often works are registered late (i.e., after publication), and how much later.

If the work was located, the copyright number was recorded and a search was made for a renewal in the volume 28 years after the date of the copyright. Lists were annotated to show whether a work had been copyrighted and renewed, or copyrighted but not renewed, or whether no entry was found at all.

\section{Searching Copyright Records at the COPYRIGHT OFFICE}

The files searched at the Copyright Office to determine copyright status were:

1. copyright card catalogs through 1977 ,

2. an online catalog of records created from 1978 forward.

3. the official copyright registers, and

4. the assignment files.

In addition, for titles determined to have been renewed, the renewal applications were searched for addresses of copyright holders. Time spent searching renewal applications was subtracted from total searching time to make it comparable with time spent searching the CCE.

The copyright card catalogs are divided into the time periods 1898 to 1937 , 1938 to 1945,1946 to 1954,1955 to 1970 , and 1971 to 1977 . The 1898 to 1937 cata $\log$ is divided into author (with some titles included) and claimant (copyright holder) files. All other catalogs combine entries for author(s), titles, and institutions (which includes publishers). The author cards are filed first, followed by titles and institution cards. Each card contains the copyright registration number for the work, date of registration, and the claimant's name. Reference staff at the Copyright Office stated that all possible bibliographic entry points should be searched; i.e., author(s), title, and institution.

The official copyright register is arranged by copyright number and by vari- ous time periods. If a copyright is renewed, the renewal number is added to the original record. The register must be searched to verify that a copyright was not renewed.

The assignment files contain information on transfer of copyright. There is an assignor catalog for 1870 to August 15, 1941, assignor/assignee catalog for August 16,1941 to 1977 and a title catalog for 1928 to 1977. Because there is no legal requirement for reporting transfers, these files are not complete.

\section{RESULTS}

Analysis of the results of the two search processes is divided into two parts: determining copyright status of monographs, and securing addresses of copyright holders.

\section{Determining Copyright Status of MONOGRAPHS}

The results of searching performed in the records of the Copyright Office are summarized in table 2 .

We found that of the 370 titles in the sample, $24 \%$ were never registered for copyright, $58 \%$ were copyrighted but not renewed, and $18 \%$ were copyrighted and renewed. For the 68 titles still protected, we assume that permission must be sought to scan and distribute them. Conversely, $82 \%$ of the titles are in the public domain and may be reformatted and distributed without further concern about copyright infringement. As expected, the percentage of copyrights renewed decreases substantially as the books get older $(11 \%$ for titles published in the 1920 s versus $39 \%$ for titles published in the 1940s).

The 68 titles renewed constitute $24 \%$ of the subset of 283 titles that were originally registered for copyright (370 minus the 87 that were never copyrighted), compared with the Copyright Office finding (Library of Congress 1994) of a $4.1 \%$ renewal rate for books and pamphlets. We believe the discrepancy between our findings and those of the Copyright Office 
TABLE 2

Copyright Status of Sample Monographs Published 1920-1950.

\begin{tabular}{lrrrrrrr}
\hline \multirow{2}{*}{$\begin{array}{c}\text { Time } \\
\text { Period }\end{array}$} & \multicolumn{1}{c}{ No. } & \multicolumn{1}{c}{$\begin{array}{c}\text { Never Copyrighted } \\
\text { \# }\end{array}$} & \multicolumn{1}{c}{$\begin{array}{c}\text { Copyright and Not } \\
\text { Renewed }\end{array}$} & \multicolumn{2}{c}{ Copyright and Renewed } \\
& \multicolumn{1}{c}{ \% } & \multicolumn{1}{c}{$\#$} & $\%$ & \# & $\%$ \\
\hline $1920-29$ & 179 & 37 & 21 & 123 & 69 & 19 & 115 \\
$1930-39$ & 99 & 27 & 27 & 59 & 60 & 13 & 13 \\
$1940-49$ & 82 & 20 & 24 & 30 & 37 & 32 & 39 \\
1950 & 10 & 3 & 30 & 3 & 30 & 4 & 40 \\
TOTAL & 370 & 87 & 24 & 215 & 58 & 68 & 18 \\
\hline
\end{tabular}

study can be explained by two factors.

1. The Copyright Office data lumps two separate categories, pamphlets and books, into one renewal category. It is entirely possible that the renewal rate on pamphlets is considerably lower than that of books alone.

2. The renewal rate on a group of qualitatively selected, core scholarly monographs might reasonably be far higher than that of books and pamphlets as a whole.

We believe the results obtained in searching the records of the Copyright Office are authoritative. Searching was conducted in strict accordance with the instructions of the staff of the Copyright Office by a highly experienced, meticulous library professional. A total of 81 hours of professional search time was spent determining the copyright status of 370 monographs, an average of $13 \mathrm{~min}$ utes per title.

Initial searching at Cornell on the same set of titles was conducted by a combination of student assistants and preservation technicians. A total of 31 hours was spent in preliminary searching at Cornell of the $C C E$, an average of 5 minutes per title.

Comparing the initial search results for the same 370 titles in the print $C C E$ at Cornell with the results obtained at the Copyright Office allowed us to evaluate the accuracy of the CCE searching. We were able to identify changes in search procedures that would improve the accuracy of the CCE searches. When these procedural changes were implemented and the searches showing discrepancies were repeated in the $C C E$, we found a 97\% agreement overall between the results obtained in searching at the Copyright Office and those obtained in CCE searching at Cornell. The procedural changes added an average of 2 minutes per title to the search time, bringing the final search time to 7 minutes per title.

What follows is a detailed analysis of:

1. the original discrepancies in the results of the two search procedures,

2. the reasons for those discrepancies, and

3. what we learned in the process and how we adjusted searching procedures on the basis of this experience.

Discrepancies in the initial search results were found in $22 \%$ of the cases ( 81 of 370 titles). The $C C E$ search was repeated for each of these 81 titles by a preservation technician experienced in bibliographic searching to determine whether the correct information was actually included in the CCE and to account for each discrepancy in search results.

Discrepancies were categorized, and each case and category of discrepancy was studied to determine whether and how it could be eliminated through procedural changes when searching the $C C E$. We found that 69 of the 81 discrepancies ( $85 \%$ of all discrepancies in searching) could be easily explained and corrected in the CCE searching (see table 3). Another 12 discrepancies in searching were determined either to be uncorrectable or to take such an extreme effort to correct as to be unreasonable (see table 4). Note that two categories of discrepancies (pamphlets and author problems) appear on 
TABLE 3

Searching Discrepancies-Easily Corkected.

\begin{tabular}{|c|c|c|c|c|c|c|c|c|c|c|c|c|c|c|}
\hline & \multicolumn{2}{|c|}{$\begin{array}{c}\text { Year } \\
\text { Earlier }\end{array}$} & \multicolumn{2}{|c|}{$\begin{array}{l}\text { Year } \\
\text { Later }\end{array}$} & \multicolumn{2}{|c|}{$\begin{array}{c}\text { Human } \\
\text { Error }\end{array}$} & \multicolumn{2}{|c|}{ Pamphlets } & \multicolumn{2}{|c|}{ Serials } & \multicolumn{2}{|c|}{$\begin{array}{l}\text { Author } \\
\text { Problems }\end{array}$} & \multicolumn{2}{|c|}{ TOTAL } \\
\hline & $\#$ & $\%$ & $\#$ & $\%$ & $\#$ & $\%$ & $\#$ & $\%$ & $\#$ & $\%$ & $\#$ & $\%$ & \# & $\%$ \\
\hline Copyright & 0 & 0 & 20 & 5 & 10 & 3 & 3 & 1 & 2 & 0.5 & 1 & 0.3 & 36 & 10 \\
\hline Renewals & 29 & 8 & 0 & 0 & 4 & 1 & 0 & 0 & 0 & 0.0 & 0 & 0.0 & 33 & 9 \\
\hline TOTAL & 29 & 8 & 20 & 5 & 14 & 4 & 3 & 1 & 2 & 0.5 & 1 & 0.3 & 69 & 19 \\
\hline
\end{tabular}

both tables 3 and 4 , indicating that certain types of problems in these categories are easily correctable, while others are not.

Table 3 presents those categories of search discrepancies where a second search of the CCE yielded correct information. Thus, the information found in the Copyright Office was found to be in the $C C E$, and could be located with reasonable and affordable procedural changes. Discrepancies are divided into two categories: those concerning information about original copyright, and those concerning information about renewal of copyright. Frequency of occurrence of each discrepancy is expressed as a percentage of the 370 titles searched.

Of the 69 correctable discrepancies, 36 (10\% of all searches conducted) concerned the determination of original copyright, and 33 (9\%) concemed whether or not the original copyright on a title was renewed.

The two largest categories, "Year Earlier" and "Year Later," are easily remedied. In searching at the Copyright Office it was found that in 29 cases, renewals ( $13 \%$ of all renewals) were registered in the 27 th year after copyright rather than the 28th year. Similarly, 20 titles were found to have been registered for copyright a year later than the date appearing on the publication. These combined 49 cases (60\% of all discrepancies) are easily corrected by changing $C C E$ search procedures to accommodate early renewal and late registration (i.e., by searching for copyright a year later than date of publication, and by searching for renewals on the 27th and 28th year after registration). This change added about one minute per title to the $C C E$ search procedure.

Human error was found to be the source of 14 discrepancies in search results ( $4 \%$ of all searches), with 10 of these instances occurring in relation to the determination of original copyright rather than renewal. These errors included oversight (due, we believe, to the use of insufficiently experienced student searchers) and spelling errors on the lists from which searches were conducted (correctable by searching from the book in hand). We are confident that searching from the book in hand and using only highly experienced searchers would correct these errors.

Six discrepancies were due either to searching in the wrong class of materials in the $C C E$ (i.e., titles weren't recognized as pamphlets rather than books) or to searching under the wrong author heading. We discovered that these discrepancies can be corrected by using only highly experienced searchers. As an additional safeguard, we also revised the searching procedure to include a review of the searching results by a librarian highly experienced in bibliographic searching. This change required complete double checks of searching on possible renewal of titles with complicated authors (e.g., corporate entries) and titles that might possibly be pamphlets or parts of a serial. The addition of these checks by a professional librarian added another minute per title on average.

Table 4 summarizes those categories of discrepancies where the "correct" information either was not included in the $C C E$, or where finding it would necessitate procedural changes that would take work well beyond what could be consid- 


\section{TABLE 4}

Searching DiscrepancieS-Unavoidable or Not Worth EFForT.

\begin{tabular}{lcccccccccc}
\hline \hline & \multicolumn{3}{c}{$\begin{array}{c}\text { 2 } \\
\text { 2 More Years }\end{array}$} & \multicolumn{3}{c}{ Pamphlets } & \multicolumn{3}{c}{ Author Problems } & \multicolumn{3}{c}{ Unexplained } & \multicolumn{2}{c}{ TOTAL } \\
& $\#$ & $\%$ & $\#$ & $\%$ & $\#$ & $\%$ & $\#$ & $\%$ & $\#$ & $\%$ \\
\hline Copyright & 3 & 0.8 & 3 & 0.8 & 3 & 0.8 & 3 & 0.8 & 12 & 3.2 \\
Renewals & 0 & 0.0 & 0 & 0.0 & 0 & 0.0 & 0 & 0.0 & 0 & 0.0 \\
TOTAL & 3 & 0.8 & 3 & 0.8 & 3 & 0.8 & 3 & 0.8 & 12 & 3.2 \\
\hline
\end{tabular}

ered reasonable effort.

Searching at the Copyright Office identified 3 titles out of the 370 that were registered for copyright two or more years after the date of publication. We had been warned by the Copyright Office staff that a work published in this time frame $(1920$ to 1950$)$ could be registered at any time within 28 years of its publication. Searching through 28 annual volumes of the $C C E$ for a yield of less than $1 \%$ (none of which, it turns out, was later renewed) is beyond the level of effort that can be reasonably expected in determining copyright status.

For reasons we could not fathom, three titles turned out to be registered as pamphlets, although they did not fit any normal definition of a pamphlet. Similarly, three titles were registered under author entries which could not reasonably be anticipated (e.g., one title was entered under the name of the publisher). Three other titles ("Unexplained") were found to be copyrighted by searching the various files at the Copyright Office, but there was no registration found under any entry we tried in the $C C E$. This latter category seems to be a measure of the actual discrepancy in information contained in the $C C E$ and that held in the files of the Copyright Office: $0.8 \%$.

We feel strongly that there is no reasonable remedy available to overcome these inevitable deficiencies and vagaries in an enormous and complex record keeping system. In fact, we are amazed at the high degree of accuracy and agreement found in the various records, published and unpublished, of the Copyright Office.

Thus, a final overall agreement in search results was achieved in $97 \%$ of all titles searched by our revised search procedures, and $100 \%$ agreement in the case of renewals. None of the discrepancies resulting from the $3 \%$ of anomalous cases concerned actual renewal, and therefore would not affect anyone's copy rights.

The revisions we made to the $C C E$ search procedure raised costs somewhat by:

1. requiring the use of more experienced search staff,

2. adding a professional staff review of results, and

3. adding a few more search points (e.g., a year earlier and a year later).

With these changes the average search time for determining copyright status by searching the CCE increased from 5 to 7 minutes per title.

\section{SECURING AdDRESSES OF COPYRIGHT HOLDERS}

The addresses of copyright holders are found only in the renewal records located in the Copyright Office and are not included in the CCE. Addresses for the copyright holders were obtained from renewal applications for the original works or renewal applications for later works by the same claimant if such were located in the online file. A number of these latter applications were filed by heirs of the original claimants. Finding and transcribing addresses took an average of 5 minutes per title. The addresses on the renewal applications ranged from 1947 to 1994 with half being 20 years or older. Only $17 \%$ of the addresses found were from the period 1990-94. 


\section{Conclusions}

Searching the same set of materials in both the widely available CCE and the files located in the U.S. Copyright Office indicates a $97 \%$ agreement in results between the two. Careful analysis of the discrepancies reveals that none of the differences involves the question of renewal of copyright. Thus our investigation demonstrates that the CCE is $100 \%$ accurate (compared with the files of the Copyright Office) in recording copyright renewals for agricultural sciences monographs. In a sense, this finding simply confirms the statement that "The CCE is in effect the Card Catalog published in book form (and since 1979 in microfiche), but it may contain more comprehensive information and should be consulted in problematic searches" (Library of Congress 1993, p. 2). But it goes beyond this to provide solid data on which to base a procedure for efficient copyright searching on large numbers of monographs in other disciplines as well. While there may well be variations by discipline in the rate of renewal of copyright, it seems highly unlikely that the degree of accuracy of the $C C E$ as an official record of copyright information will vary by discipline.

We believe this study clearly establishes that one can reliably determine the copyright status of books published before 1950 without traveling to Washington, or contracting with the Copyright Office or a commercial search company to undertake time-consuming searches in the complex files of the Copyright Office. A standard of reasonable effort in this area must rely on authoritative and widely available sources, such as the $C C E$, the official published record of the Copyright Office. It must also be based on a large enough sample to take into account varying situations. Our $14 \%$ sample represented the range of problems encountered in the monographs of the core historical literature of agricultural sciences. With a finding of $100 \%$ agreement in renewal searches in the CCE and $97 \%$ agreement overall, we assert that the $C C E$ is an authoritative source for determining the copyright status of monographs pub- lished before 1950. The procedure detailed in Appendix $A$ is presented as a generalizable standard of reasonable effort for libraries to use in determining the copyright status of books.

By spending an average of 7 minutes per title searching locally in the $C C E$, we were able to replicate the results of nearly twice the time searching in the Copyright Office. (If the CCE from 1920 to 1978 were made available online, searching time could be reduced considerably and access to the CCE improved.) We determined that $18 \%$ of the sample are still copyrighted. Thus a fairly modest local searching effort reduced the size of our copyright permissions problem by $82 \%$. Assuming this is a reliable estimate of the percentage of core historical agriculture monographs still under copyright, we now face the challenge of contacting copyright holders and securing permissions for the approximately 469 titles (18\% of 2,608 monographs published between 1920 and 1950) that are still protected.

We hope these findings will help to alleviate some of the confusion about how to proceed with systematic preservation of brittle books published in the past 75 years, and with scanning of older materials for inclusion in digital libraries. However, this is only one of many copyright and preservation issues in need of clarification. Ultimately the Copyright Office may decide to issue guidelines on copyright and preservation, or Congress may amend the copyright law. In any case, such guidelines or statutory changes will stem from discussions among the legal, library, author, and publishing communities. We believe verifiable results from carefully constructed pilot projects are needed to inform these negotiations. Hard data from systematic library and publisher investigations of the issues will help keep this essential process of give and take rational and constructive. In the end, we believe such data will help to secure terms which will facilitate, rather than impede, the national preservation effort.

\section{TOPICS FOR FURTHER INVESTIGATION}

Having developed guidelines for deter- 
mining copyright status of U.S. monographs published before 1951, we must now work out reasonable effort procedures for contacting copyright holders and seeking permissions. We are currently in the process of contacting all rights holders, and based on our experience we plan to develop a standard for locating copyright holders and seeking permission to convert protected materials for preservation and access. Finally, we hope to establish precedents for negotiating royalty payment amounts and mechanisms. In addition, we must address the problem of copyright on the 339 serial publications in the core historical literature of the agricultural sciences. Given the complexity of copyright searching and the large number that have already been filmed commercially, we are likely to employ a very different strategy for serials.

The findings reported here were made after intensive analysis of a body of agricultural sciences literature. It would be interesting to investigate variations by discipline in the rate of renewal of copyright. We hope others will replicate, adapt, and improve on our procedures in other disciplines, and publish the results.

We urge librarians to conduct replications of our study and to undertake pilot investigations for determining the copyright status of other forms of intellectual property, such as pamphlets, sound recordings, visual arts, maps, and motion pictures and film strips. Work is also needed to determine copyright status of foreign imprints targeted for preservation and to undertake pilot investigations to determine the copyright status of other forms of intellectual property, such as pamphlets, sound recordings, visual arts, maps, and motion pictures and film strips. Work is also needed to determine copyright status of foreign imprints targeted for preservation.

\section{Works CITED}

Demas, Samuel. 1994. Setting preservation priorities at mann library: A disciplinary approach. Library hi tech, 12 (47): 3.

Guinan, Jr., James J. 1961. Duration of copyright. In Copyright law revision. Studies prepared for the Subcommittee on Patents, Trademarks, and Copyrights of the Committee on the Judiciary, United States Senate, 86th Congress, first [-second] session, 82. Washington, D.C.: U.S. Govt. Print. Off.

Gwinn, Nancy E. 1993. A national preservation program for agricultural literature, United States Agricultural Information Network, 16 May.

Library of Congress. Copyright Office. 1993. The copyright card catalog and the online files of the Copyright Office. Circular 23: 2.

Library of Congress. Copyright Office. 1995. How to investigate the copyright status of a work. Circular 22: 3.

Murphy, Henry T. and Dorothy W. Wright. 1993. Primary historical literature, 18601949. In Literature of animal science and health, 322-398. Ithaca, N.Y.: Cornell Univ. Press.

Oakley, Robert L. 1990. Copyright and preservation: A serious problem in need of a thoughtful solution. Washington, D.C.: Commission on Preservation and Access.

Olsen, Wallace C. 1991. Agricultural economics and rural sociology: The contemporary core literature. Ithaca: Cornell University Press.

Thompson, Susan J. and Carl W. Hall. 1992. Primary historical literature, 1850-1950. In The literature of agricultural engineering, 339-405. Ithaca, N.Y.: Cornell Univ. Press. 


\section{APPENDIX A}

\section{STANDARD OF REASONABLE EFFORT}

\section{Procedure for determining copyright status of monographs published in the U.S. before 1950, using the Catalog of Copyright Entries}

\section{Sources Of Copyright Information}

The Catalog of Copyright Entries is the official record of the U.S. Copyright Office. The CCE has been found to be a reliable tool in determining the copyright status of a work and the name of the claimant at the time of original registration and renewal. However, the $C C E$ does not include the addresses of copyright holders or any information about later assignments or transfers of copyright.

The $C C E$ is available in printed form to 1979 , after which it was issued in microfiche form only. The $C C E$ is divided into parts according to the classes of works registered (e.g., Books). Each volume of the $C C E$ contains entries for registrations made during a particular year, with the entries for renewals in a separate section. For copyright records beginning in 1978, an online catalog is available through LC Marvel gopher://marvel. loc.gov:70/11/copyright.

Before commencing a copyright search process, read Circular 22 of the Copyright Office "How to Investigate the Copyright Status of a Work." The Copyright Office has available a series of other useful circulars on various aspects of copyright. Questions about copyright searching can be answered by the staff of the Reference and Bibliography Section of the U.S. Copyright Office (202-707-6737).

\section{Staffing Level And Logistics}

Searching should be done by experienced, accurate bibliographic searchers with knowledge of forms of entry, corporate authors, and characteristics and variations in the forms of monographic publications. The results of all searches should be reviewed by a librarian experienced in bibliographic searching.

The "Books" portion of the CCE for 1920-77 takes 24 linear feet of shelf space. Efficient searching of a large number of titles requires that the entire set be shelved together in proximity to a table and chair which can be used for concentrated, quiet searching. Ideally, searching should proceed from the books in hand (or from a photocopy of the title page and verso) rather than from a list of publications. Results of prior bibliographic searches (e.g., in RLIN and OCLC), placed in the books for convenience, can provide useful clues for complex titles.

\section{Procedure}

1.0 Works published more than 75 years ago are in the public domain and do not require copyright searches.

2.0 Examine the book carefully.

2.1. Look for a copyright symbol and date. Lack of a notice of copyright is a fatal defect, so publications with no copyright notice may be presumed to be in the public domain.

2.2 Look for evidence that the book may be part of a series, multivolume work, or serial. Search the appropriate sections of the CCE (e.g., Pamphlets or Serials) if necessary.

3.0 Search the correct $C C E$ volume indexes under both author and title to find an entry indicating that the work was registered for copyright. If there are multiple authors, search all of them. Note that the arrangement of volume indexes varies over time. If you have difficulty finding any copyrighted titles for a year, be suspicious and look through the volume again to be sure you have found all the indexes.

If no copyright registration is found for the year of publication (usually the same as the date by the copyright symbol in the book), search as above in the volume for the following year.

If a copyright registration is found, note the month and year it was copyrighted and the copyright number.

4.0 When a copyright registration is found, add 28 years to the year of initial copyright and search the author(s) and title in the renewals index of that year (i.e, if a book was copyrighted in 1922 , search 1950 for a renewal). If no renewal is found in the 28 th year, search as above in the 27 th year after initial registration.

If a copyright renewal is found, note the renewal number and the name of the copyright holder.

5.0 Have an experienced professional librarian review search results. In this review, titles with the following characteristics should be re-checked in the appropriate volume(s):

1. published in multiple editions;

2. corporate or multiple authors;

3. may be part of a serial publication, or may be a pamphlet.

6.0 Works for which no renewal was found using these procedures may be presumed to be in the public domain. 